\title{
A Comunicação na Circulação do Capital em Contexto de Plataformização
}

\author{
Communication in the Circulation of Capital in the Context of \\ Platformization
}

Rafael Grohmann*

\section{RESUMO}

O artigo teoriza sobre o papel da comunicação na circulação do capital em contexto de plataformização. Para tanto, discute sobre capitalismo de plataforma e plataformas digitais como meios e tecnologias de produção, comunicação e circulação. Analisa como, a partir disso, há uma circulação comunicacional do capital envolta em racionalidade neoliberal, a partir de eixos articuladores da linguagem e do trabalho. Então, problematiza como a comunicação pode engendrar lutas por circulação que vá além do realismo capitalista.

Palavras-chave: Circulação do Capital; Capitalismo de Plataforma; Gramática do Capital; Plataformização; Trabalho.

\begin{abstract}
The article aims to theorize about the role of communication in the circulation of capital in the context of platformization. Thus, it discusses platform capitalism and digital platforms as means and technologies of production, communication and circulation. It analyzes how there is a communicational circulation of capital wrapped in neoliberal rationality, based on articulating axes of language and labor. Then, it problematizes how communication can engender struggles for circulation that go beyond capitalist realism.
\end{abstract}

Kewords: Circulation of Capital; Capital Grammar; Labor; Platform Capitalism; Platformization.

\section{INTRODUÇÃO}

Atualmente, a comunicação atua como braço-auxiliar do capital em um combo de financeirização (AUTOR, 2019), racionalidade empreendedora/neoliberal (DARDOT; LAVAL, 2016) e plataformização (VAN DIJCK; POELL; DE WAAL, 2019), enquanto sínteses sociais nos termos de Sohn-Rethel (2017), isto é, múltiplas ligações ou particularidades (LUKÁCS, 2012), no sentido de uma condição geral de produção, em sentido marxiano.

Nos últimos anos, surgiram expressões que adjetivam o capitalismo, como sendo de plataforma, informacional, vigilância, de dados, digital ou algorítmico, a partir de obras como as de Srnicek (2017) e Zuboff (2019). Em outro ângulo, Huws (2019) defende que a questão terminológica é menor frente ao fenômeno a ser compreendido e enfrentado e é preciso capturar o que realmente muda qualitativamente no capitalismo. Para Dyer-Witheford, Kjosen e Steinhoff (2019),

\footnotetext{
* Doutor em Ciências da Comunicação pela Universidade de São Paulo (USP). Professor do Programa de Pós-Graduação em Ciências da Comunicação da Universidade do Vale do Rio dos Sinos (UNISINOS). Av. Cristo Rei, 983 - São Leopoldo/RS. Telefone: (51) 3591-1122. E-mail: rafael-ng@uol.com.br.
} 
trata-se de considerar questões como inteligência artificial, plataformas e dados como condição geral de produção no capitalismo contemporâneo.

Aqui adotaremos a nomenclatura "capitalismo de plataforma", que, para nós, significa, a um só tempo, as inter-relações das sínteses sociais acima, isto é, financeirização e racionalidade neoliberal. Não é possível compreender as plataformas ensimesmadas, como se fossem alheias às outras relações do mundo (GROHMANN, 2020). Ou seja, não compreendemos as relações entre capitalismo e plataformas digitais como causa-efeito nem com qualquer tipo de determinismo, mas como um feixe de relações e contradições. Srnicek (2017) não chega a conceituar o que chama exatamente de capitalismo de plataforma, apenas acenando para o fato de ser central a extração de valor a partir de dados, o que Sadowski (2019) também fala ao analisar os dados como forma de capital.

Consideramos, a partir de Srnicek (2017), Van Dijck, Poell e De Waal (2018) e Couldry (2019), as plataformas como infraestruturas digitais e de conexão abastecida por dados e algoritmos e tendo por algumas funções perfilamento e vigilância, com valores e normas inscritos em suas arquiteturas e interfaces - o que dá a ver também as distintas formas de extração de valor - que não são únicos. Talvez, em vez de considerar a inteligência artificial como condição geral de produção, como fazem Dyer-Witheford, Kjosen e Steinhoff (2019), seja o caso de considerar as plataformas como o eixo onde também está presente a inteligência artificial, já que esta nada mais é do que decisões automatizadas baseadas em dados.

A maior parte dos estudos sobre capitalismo de plataforma e suas derivações, como as obras supracitadas - e poderíamos acrescentar Couldry e Mejias (2019) e Graham (2019) - não tratam do papel da comunicação em relação ao modo de produção capitalista, sendo que a faceta comunicacional é crucial para o êxito e as mudanças no capitalismo'. A Economia Política da Informação, da Comunicação e da Cultura tem como uma de suas bases compreender como esses aspectos são centrais para o modo de produção capitalista, o que é expresso inclusive em pesquisas de brasileiros sobre trabalho digital como Dantas (2014) e Bolaño e Vieira (2014).

Neste artigo, de cunho teórico, analisamos o papel da comunicação - que está presente na luta de classes, na ideologia, nas extrações de valor - na circulação do capital. A comunicação, de alguma forma, articula os sentidos do capital e faz com que eles circulem por todos os lugares da sociedade, em uma lógica neoliberal. Assim, o texto analisa as relações entre comunicação e circulação do capital em contexto de capitalismo de plataforma. Em seguida, trata das tecnologias de circulação, para, então, mostrar como linguagem e trabalho são eixos articuladores do papel da comunicação na circulação do capital. Enfim, problematizamos como a comunicação pode entrever lutas por circulação que vá além do realismo capitalista (FISHER, 2011).

\section{CIRCULAÇÃO DO CAPITAL E COMUNICAÇÃO}

Consideramos o capital, assim como Harvey (2018), enquanto valor em movimento. E esses movimentos, assim como a circulação do capital, não se fazem no vazio. Há, pois, como argumenta Antunes (2018), um processo de produção envolvido no

\footnotetext{
${ }^{1}$ Por outro lado, muitas vezes, as pesquisas em comunicação tratam da economia política como se fosse algo exógeno ou estrangeiro à área. Isso se passa quando há a tentativa de prescrever algo puramente comunicacional - como se falar de "circulação" na comunicação fosse somente tratar de "circulação midiática".
} 
processo de circulação. Nos três volumes d'O Capital, Marx (2013; 2015; 2017) elabora uma sofisticada análise dos processos de valorização, realização, distribuição de valor e captura do capital (HARVEY, 2018). Inclusive, no volume II, o autor mostra como há propensão ou incentivo à permanente aceleração da circulação do capital. Mas é mesmo nos Grundrisse (MARX, 2011), nos trechos conhecidos como fragmentos sobre as máquinas (ou maquinarias), em que ele dá as pistas para pensar o papel da comunicação na circulação do capital.

Os meios de transporte e de comunicação servem para acelerar a circulação do capital, segundo Marx (2011, p. 134), "no duplo de sentido de que determina tanto o círculo daqueles que trocam entre si, dos que entram em contato, como a velocidade com que a matéria-prima chega aos produtores e o produto, aos consumidores" (MARX, 2011, p. 134). Isso reduz o tempo morto e o de rotação. Essa aceleração se relaciona a um transbordar

\footnotetext{
"das esferas da produção e da comercialização e altera fundamentalmente os ritmos da vida cotidiana. Aceleração na produção em determinado momento exige aceleração no consumo (daí a importância da moda e da obsolescência programada)" (HARVEY, 2018, p. 41).
}

A aceleração da circulação do capital em contexto de plataformização pode ser explicada, em alguma medida, pela explosão de aplicativos que conjugam, justamente, um meio de comunicação com meios de transporte, como Uber, iFood e Rappi - com trabalhadores transportando pessoas e distintos tipos de objeto a partir do gerenciamento e controle das plataformas, que organizam, inclusive, o fluxo espacial das cidades (MOROZOV; BRIA, 2019). A circulação e a não circulação de pessoas e mercadorias se dá por intermédio das empresas de plataformas, com a vigilância de seus rastros digitais (BREITER; HEPP, 2018), inclusive com o apoio do Estado, como mostram Morozov e Bria (2019), sedimentando a figura de um "Estado empreendedor" (DARDOT; LAVAL, 2016) a partir da circulação de sentidos de "inovação" e "transformação digital” trazidas por essas plataformas.

Essa logística entrecruzada entre meios de transporte e meios de comunicação no capitalismo de plataforma, enquanto elemento crucial da circulação do capital, só é possível a partir de infraestruturas materiais. Não é o predomínio da "nuvem" ou do "trabalho imaterial", mas de materialidades do trabalho e das infraestruturas de comunicação. Como lembra Murdock (2018), não podemos esquecer que a comunicação é feita de matéria-prima, recursos naturais e não naturais e cadeias de trabalho por trás da construção das infraestruturas digitais, que "demandam cada vez mais minerais, materiais e energias escassos em sua produção e em seu uso" (MURDOCK, 2018, p. 359).Trata-se, então, de tecnologias, inclusive comunicacionais e informacionais, que auxiliam na circulação do capital.

\section{TECNOLOGIAS DE CIRCULAÇÃO E PLATAFORMAS DIGITAIS}

As tecnologias servem, ao mesmo tempo, à circulação do capital e são fruto do trabalho humano. Segundo Vieira Pinto (2005, p. 177), "a palavra 'técnica' desligada da essencial relação com o trabalho humano, em sua expressão mais geral, permanece no plano da abstração, no estado de "ideia entificada". Assim, trata-se de uma visão que contempla a relação dos sujeitos sociais em suas vidas concretas e das instituições com as tecnologias. Como afirma Marx (2013, p. 446), em nota de rodapé d'O Capital, "a tecnologia desvela a atitude ativa do homem em relação à natureza, o 
processo imediato de produção de sua vida e, com isso, também de suas condições sociais de vida". Nos Grundrisse, antes d'O Capital, Marx (2011) já concebia "maquinaria" como elemento tecnológico do processo de produção do capital, com ênfase no protagonismo do trabalho humano. Segundo o autor,

\begin{abstract}
a natureza não constrói máquinas nem locomotivas, ferrovias, telégrafos elétricos, máquinas de fiar automáticas etc. Elas são produtos da indústria humana; material natural transformado em órgãos da vontade humana sobre a natureza ou de sua atividade na natureza. Elas são órgãos do cérebro humano criados pela mão humana; força do saber objetivada (...). Até que ponto as forças produtivas da sociedade são produzidas, não só na forma do saber, mas como órgãos imediatos da práxis social; do processo real da vida (MARX, 2011, p. 589).
\end{abstract}

Harvey (2018) explica que a noção marxiana de tecnologia envolve não só máquinas e hardwares, mas "formas de organização [...] e o software de sistemas de controle, estudos de tempo e movimento" (HARVEY, 2018, p. 22). Ou seja, as tecnologias atuam como organizadora tanto da produção quanto de sua própria organização, além dos sentidos que elas circulam a partir dessa organização. Assim, o desenvolvimento tecnológico no modo de produção capitalista se relaciona com a capacidade de "elevar a produtividade da mão de obra e aumentar a eficiência e a velocidade de rotação do capital tanto na produção quanto na circulação" (HARVEY, 2018, p. 122).

Podemos compreender que as tecnologias são, a um só tempo, de produção, comunicação e circulação. Indo além da definição explicitada na introdução deste texto, propomos pensar as plataformas, ao mesmo tempo, como meios de comunicação e meios de produção, enquanto infraestruturas de conexão (COULDRY, 2019) e circulação. A homologia comunicação-produção, colocada por Williams (2011), auxilia a compreender o papel da comunicação na circulação do capital, considerando que "a comunicação e os seus meios materiais são intrínsecos a todas as formas distintamente humanas de trabalho e de organização social” (WILLIAMS, 2011, p. 69), relacionando-se tanto às forças produtivas quanto às relações de produção. Isso mostra o entrelaçamento entre comunicação e trabalho no capitalismo de plataforma, enquanto fatores essenciais de sua sustentação.

Uma plataforma é, a um só tempo, lugar de trabalho, produção, interação, sociabilidade e circulação de sentidos, valor e capital. É produzida a partir de trabalho humano em diversas dimensões do trabalho digital (QIU; GREGG; CRAWFORD, 2014; FUCHS; SANDOVAL, 2014). Após desenhada, a plataforma é um espaço - com modulações programadas - para distintas atividades de trabalho, como mostram as distintas tipologias de plataformas de trabalho, que explicitamos em artigo anterior (GROHMANN, 2020). Podem ser usadas tanto para controle e gerenciamento inclusive algorítmico - quanto espaços para interação e organização dos trabalhadores, como têm mostrado pesquisas sobre novas formas de organização dos trabalhadores em plataformas digitais, tais como Cant (2019) e Woodcock e Graham (2019).

As tecnologias de circulação auxiliam a "encurtar o tempo de circulação do capital na produção e no mercado" (HARVEY, 2018, p. 99), ou seja, tem como função auxiliar a aceleração da própria circulação do capital, ajudando, inclusive, na disseminação de dados. Harvey (2018) exemplifica a partir da Netflix: "o valor implicado na produção e na transmissão do filme por meio de complexas infraestruturas de comunicação é recuperado pelos milhões de usuários que assinam a Netflix" (HARVEY, 2018, p. 195). 
Isto é, há extração de riqueza principalmente na fase de distribuição - o que no mercado financeiro se chama de "potencial de escalonamento", isto é, o valor extraído a partir da distribuição. Este é um ponto crucial para compreensão da circulação do capital em contexto de plataformização: como as próprias plataformas digitais - com seus conteúdos, dados e processos produtivos - circulam como forma de capital (SADOWSKI, 2019), com extração de mais-valia?

As tecnologias de circulação também redefinem as noções de espaço e tempo no âmbito da circulação do capital. Há um vetor do próprio capital que atua nos modos de circulação do tempo e dos espaços, considerando que "a circulação e a acumulação do capital ocorram numa configuração espaço temporal específica" (HARVEY, 2018, p. 132).

Wajcman (2015) mostra como as práticas temporais são sociomateriais e dependem de questões de classe e gênero e também se relacionam com as reorganizações do mundo do trabalho e do próprio capital. As percepções de uma "sociedade acelerada" não são iguais para os diferentes sujeitos e também não se devem exclusivamente às tecnologias, mas à própria circulação do capital. Nesse sentido, a autora fala em "tecnologias de aceleração" e coloca o trabalho em mídias digitais como um de seus maiores exemplos.

As percepções de aceleração da vida cotidiana, em alguma medida, se relacionam com o espraiamento da lógica capitalista a todos os domínios da vida, o que Wendy Brown (2016) chama de disseminação da razão neoliberal. Isso é demonstrado em pesquisa de Wajcman (2019) sobre a produção de calendários a partir dos engenheiros do Vale do Silício, cuja construção de tempo é marcada por parâmetros neoliberais de performance, mercadorização e otimização do tempo.

Em contexto de capitalismo de plataforma, o tempo de circulação de mercadorias está alinhado à circulação do capital e seu potencial produtivo-comunicacional, isto é, em consonância com a lógica capitalista neoliberal do tempo, em que tempo de trabalho e tempo de não trabalho tem suas fronteiras diluídas. Isso significa dizer que os movimentos de circulação do capital, como vimos construindo na argumentação, não se referem a uma ação que é puramente econômica, mas transforma todos os momentos e dimensões da vida social. A naturalização e a justificação desses modos de vida ocorrem devido ao papel da comunicação na circulação do capital.

A circulação desenfreada de conteúdos por meio das plataformas digitais - que, pelo suas próprias arquiteturas, facilitam esse tipo de circulação - é chamada por Dean (2008) de capitalismo comunicativo, no sentido de que há uma política da despolitização nessa circulação de conteúdo. Esse é o próprio sentido da economia política das plataformas - o valor da circulação por ele mesmo. Isso significa dizer que a comunicação mobiliza os sentidos e a própria circulação de mercadorias, contribuindo para a aceleração dos fluxos do capital e seus movimentos espaçotemporais. Enquanto tecnologias de produção, comunicação e circulação, as plataformas digitais necessitam de ancoragens linguageiras/discursivas e dos processos produtivos para sua existência e solidificação no modo de produção capitalista.

\section{LINGUAGEM E TRABALHO EM CIRCULAÇÃO}

A circulação comunicacional do capital apresenta alicerces, isto é, dimensões fundamentais que auxiliam nos processos circulatórios: a linguagem e o trabalho, tomados como um binômio inseparável e que forma, conjuntamente, a atividade de 
comunicação (FÍGARO, 2018). Esse “combo" contribui para reprodução e transformação da sociedade e do próprio capital. A atividade de linguagem em conjunto com a atividade de trabalho (work) forma um conjunto com possibilidades de criação, podendo fazer circular sentidos novos. Já a linguagem com o trabalho como labour ${ }^{2}$ - enquanto força de trabalho ou trabalho alienado, ou seja, o trabalho inserido nos processos produtivos do capital - é o que auxilia a correr as engrenagens do capital, muitas vezes apropriando-se do combo linguagem-work para dar uma aparência de "novidade" à dimensão discursivo-narrativa do capital.

As palavras circulam a partir de condições materiais concretas, e elas próprias podem ser consideradas atividades de trabalho (NOUROUDINE, 2002), que, por sua vez, fazem circular sentidos a partir de suas próprias materialidades e dos processos produtivos, que contêm também atividades linguageiras. A dialética dos "combos" linguagem-work e linguagem-labour é o alicerce para as "lutas por circulação", isto é, para as disputas envolvidas na circulação de sentidos e que afetam, de alguma forma, a circulação comunicacional do capital. Com isso, queremos enfatizar que a perspectiva da circulação é, por definição, uma abordagem que prioriza os movimentos. Termos como criação, reprodução, transformação e alienação não são estanques, lineares ou essencializantes, mas se dão a partir de movimentos concretos.

Na circulação comunicacional do capital, há predomínio do combo linguagem-labour, enquanto manifestação de gramáticas e materialidades predominantes do capital em circulação, mas os movimentos de linguagem-work interferem nos processos de linguagem-labour, enquanto potências que podem se posicionar fora da circulação do capital, mas acabam inserindo-se nos limites ou dentro dos processos do próprio capital. A linguagem, ela própria, torna-se capital.

Rossi-Landi (1985) segue esse caminho ao mostrar as homologias entre produção linguística e produção material e afirma que a linguagem pode ser tanto trabalho quanto mercado. Consideramos que não se trata exatamente de distinguir "trabalho" de "mercado", mas de diferenciar atividade de trabalho e força de trabalho inserida no modo de produção capitalista. Assim, é a atividade linguageira convertida em mercadoria que atua como signo do capital, ou nos processos de circulação comunicacional do capital.

Para Rossi-Landi (1985), a comunicação é constituída pela operação do capital linguístico, envolvendo "produção, circulação e acúmulo de mensagens no âmbito de uma comunidade linguística, num mercado comunicativo" (ROSSI-LANDI, 1985, p. 236). Os signos circulam como mercadorias a partir do papel da comunicação na circulação do capital.

Para Goux (1973), é preciso pensar as relações dialéticas entre economia e o simbólico, considerando a função simbólica como horizonte do signo. Tanto a circulação de mercadorias quanto a circulação de sentidos fazem parte do regime de signos linguísticos. Este é o eixo que articula financeirização e plataformização, como pontuado na introdução. Segundo Goux (1973), o "mundo da circulação" é o que produz uma comunidade de valor. Podemos considerar que o valor da linguagem na circulação do capital reside em sua circulação, como narrativas que regulam e legitimam modos de ser e aparecer do capital em contexto de capitalismo de

\footnotetext{
${ }^{2}$ Optamos aqui pela grafia britânicas a fim de não confundir com a expressão brasileira "labor", que não possui exatamente o sentido que trazemos aqui.
} 
plataforma, como expressões e práticas de "indústria 4.0", inteligência artificial, empreendedorismo, "quarta revolução industrial", entre outros.

Assim, os signos do capital são produzidos em determinados contextos - conectados a mercados linguísticos e aos circuitos do trabalho - de maneira a serem colocados não como uma visão específica de quem produz os signos, mas como algo "natural" e totalizante. Isso quer dizer que a circulação incessante dos signos do capital é o próprio capital desses signos. É na circulação que ocorre a sedimentação de uma gramática do capital imposta a todos como única possibilidade de sobreviver no mundo. Isso mostra como a comunicação é um importante elo de todo um sistema de produção e circulação de sentidos e do capital. É preciso, então, mobilizar a linguagem como capital para que outros sentidos sejam circulados. A disputa de sentidos nas lutas por circulação envolve uma luta pelos modos de circular a linguagem como labour.

Segundo Marazzi (2011), a linguagem perpassa toda a economia capitalista, produzindo formas de organização e rearticulando espaços de produção. Nessa relação entre capital e linguagem, há, processos produtivos que buscam maximizar a circulação de informações a fim de atender às demandas do mercado. A linguagem, desta forma, pode se ajustar à circulação do capital tanto na forma quanto no conteúdo, evidenciando temporalidades, espacialidades e gramaticalidades.

Os sentidos em circulação estão inseridos no modo de produção capitalista. De um lado, a linguagem em circulação do próprio capital financeiro; de outro, o capital afetando todas as linguagens possíveis, afetando inclusive os sentidos das plataformas digitais, isto é, própria linguagem é capturada pela "máquina digitalfinanceira", nos termos de Berardi (2012). Podemos considerar, assim, as próprias plataformas, a partir de Sadowski (2020) como novas formas de rentismo no capitalismo contemporâneo - de forma que é impossível separar a circulação do capital das plataformas digitais e também da gramática do capital.

\section{A GRAMÁTICA DO CAPITAL}

O capital cristaliza sentidos por meio da circulação da gramática do capital. Isso se dá a partir da sedimentação e na cristalização de sentidos dos signos circulantes do capital, em jogos de repetição e reatualização, como verdadeiros "mantras", em uma gramática legitimadora dos modos de ser e aparecer do capital nas distintas instâncias da vida social. A partir de palavras-chave que funcionam como "palavras de ordem" vão-se costurando narrativas que não só justificam a racionalidade neoliberal, mas apresentam-na como a única possível, em um "realismo capitalista" (FISHER, 2011).

Há um atenuamento do vocabulário de "luta de classes" e a adesão a uma gramática que concebe o indivíduo como responsável/responsabilizado por todos seus sucessos e fracassos, que são metrificados. É o pano de fundo para as justificativas do imperativo da "flexibilização" do trabalho, tomando o flexível sempre como positivo - como nas narrativas envoltas na plataformização do trabalho. Isto é, a gramática do capital em circulação é a faceta mais visível da racionalidade neoliberal, que justifica os modos de ser e existir das plataformas digitais.

As narrativas empreendedoras, conforme mostra Casaqui (2016), são formas de sedimentação comunicacional do capitalismo. Inspiração, "atitude de dono", mindset, performance, resiliência, proatividade, inovação, engajamento, criatividade, 
compliance, coach são palavras de ordem na gramática do capital em circulação, como um modo legítimo e único de pensar a vida em sociedade

O que queremos enfatizar é que se há "mercado linguístico" (Rossi-Landi, 1985) e signos do capital em circulação, isso só acontece atualmente pela circulação envolvendo os dispositivos comunicacionais mais variados - e, justamente, pela repetição à exaustão na multiplicidade de telas, tweets e memes - que há a sedimentação desse modo de pensar específico - neoliberal - alçado como se fosse universalidade. Jornalismo, publicidade, vídeos no Youtube, distintas plataformas digitais, Linkedln e interações midiatizadas, entrecruzadas, formam palco para a sedimentação dessas narrativas.

Enquanto fórmulas convocatórias, pois, os signos do capital estrangulam os múltiplos sentidos das expressões originais, impondo um sentido restrito, mas que deve ser aplicado a todas as pessoas - como um referente não só social, mas universal. Isso funciona a partir de "fechamentos discursivos", de modo a ajustar os sentidos à gramática do capital. Por um lado, os sentidos ainda não estão totalmente estabilizados, mas em disputa. Por outro, são reapropriados como se fossem mesmo da lógica e do predomínio do capital.

Essas fórmulas funcionam de modo a servir para quaisquer sujeitos em quaisquer épocas ou espaços. São expurgadas práticas históricas de classe, gênero, raça, trajetórias e marcadores sociais de desigualdades e diferenças. São adaptáveis a quaisquer momentos e situações, desde o mascaramento/a invisibilização da informalidade e precariedade do trabalho (como a "guerreira empreendedora que vende bolo de pote") ou aplicações a outras áreas da vida ("inove no amor", "seja a melhor versão de você mesmo", "seja um empreendedor também em seus momentos de lazer"). Esta é a embalagem discursiva do capitalismo de plataforma.

O "amor pelo trabalho" - ou o "trabalho afetivo como ideologia (ILLOUZ, 2011) também é parte da gramática do capital como dispositivo de distinção e legitimação de mérito. Faz parte das competências e habilidades requeridas pelo trabalhador para gestão de si mesmo como portfólio que está disponível em todos os momentos e plataformas. É o privilégio de colocar-se discursivamente como sujeito desinteressado nas lógicas econômicas, mas sim nas questões simbólicas e afetivas (BOURDIEU, 2007).

Assim, os signos do capital funcionam como índices de desempenho e cartão de visita sobre a posição dos sujeitos no mundo. A gramática circulante, então, funciona sob a égide de que tudo deve servir para lógicas rentáveis. À circulação dos signos, enquanto discursos, acrescenta-se a circulação das métricas (BEER, 2016), enquanto lógicas de desempenho e avaliação com mecanismos de (auto)vigilância. Como afirmam Dardot e Laval (2016), a partir dessas lógicas de eficiência e eficácia, é a própria noção de sujeito político que se modifica. Os sujeitos não devem somente aderir aos signos do capital, mas inspirar-se e motivar-se a partir deles. "Vender-se" como sujeito de mercado em todos os dispositivos comunicacionais. Essa constante reiteração por parte do sistema é não só a certeza de que haja não só uma adesão, mas um envolvimento ativo - inspirado e motivado - de forma a serem considerados parte de uma gestão da alma (DARDOT; LAVAL, 2016).

Como quaisquer circulações comunicacionais, os signos do capital também enfrentam disputas e lutas por outras circulações. A grande perversidade da racionalidade neoliberal é qualquer projeto apresentado como alternativa é, de alguma forma, capturado, ao menos em parte, aos signos do neoliberalismo enquanto regimes de visibilidade dos próprios sujeitos para conseguir se viabilizar - 
econômica e midiaticamente em contexto de plataformização. Este é o maior desafio em relação ao enfrentamento de um "realismo capitalista" (FISHER, 2011). E se, pois, a linguagem é um alicerce do capital por causa de suas ligações com a racionalidade neoliberal e a interpenetrabilidade entre linguagem e economia no modo de produção capitalista, o trabalho é um fundamento material de sua sustentação em contexto de plataformização.

\section{TRABALHO NO CAPITALISMO DE PLATAFORMA}

As discussões sobre trabalho em plataformas digitais necessitam considerar 0 necessário entrelaçamento com a racionalidade neoliberal e seus discursos, considerando as plataformas como os meios e tecnologias de produção, comunicação e circulação, algo que nem sempre está em primeiro plano na bibliografia europeia sobre o tema (WOODCOCK; GRAHAM, 2019, por exemplo).

As cadeias produtivas de valor, enquanto materialidades dos processos produtivos, fazem circular sentidos sobre as atividades de trabalho e também sobre seus produtos. Os distintos mecanismos de extração de mais-valia a partir das diferentes atividades de trabalho em um "circuito de trabalho" nos ajudam a compreender seu papel na circulação comunicacional do capital em contexto de plataformização. Essas transformações nos modos de organização da produção implicam em mudanças nos circuitos dos processos produtivos em escalas local e global, com distintas maneiras de extração do valor a partir de plataformas digitais. A partir de Sadowksi (2020), consideramos que há mecanismos rentistas nas plataformas digitais, como extração de dados, fechamento digital e convergência de capital.

As mudanças envolvidas no circuito do trabalho também envolvem, pois, dimensões jurídicas e políticas e que afetam a vida de milhões de trabalhadores, como discutimos em Grohmann e Qiu (2020) A “ideologia do Vale do Silício" (SCHRADIE, 2017) não é somente parte da mudança da gramática do capital, mas da reorganização produtiva do capital - que circula pelo mundo como "imagem do que deu certo". Os oligopólios tecnológicos projetam sentidos sobre o "capitalismo de plataforma" como marca cristalizada de "disrupção", de modelo a ser seguido, como uma fórmula convocatória que age também na dimensão do trabalho.

No mundo do trabalho marcado pelo "privilégio da servidão" (ANTUNES, 2018), com o imperativo da flexibilidade e os trabalhadores transformados em simulacros de "empreendedores de si mesmos", há de se pensar também quais as formas e direções da circulação dos trabalhadores - pelo espaço geográfico, pela economia, pela política, pelos espaços e atividades de trabalho. Como os trabalhadores circulam no capitalismo de plataforma? Como a circulação desses trabalhadores ajuda a mobilizar a circulação de mercadorias e a extração de mais valia das plataformas? Como ocorre a não circulação dos trabalhadores que não fazem parte dos circuitos de trabalho? Pensar, pois, no circuito do trabalho como alicerce da circulação comunicacional do capital é também compreender a circulação dos sujeitos que trabalham.

Considerar, então, a linguagem e o trabalho como alicerces da circulação comunicacional do capital é entender tanto os signos que circulam como work e labour como o próprio trabalho que circula a partir dos sujeitos sociais, que estão envolvidos nos circuitos de produção, sempre também marcados por processos comunicacionais. Tanto os signos quanto as materialidades do trabalho expressem índices de racionalidade neoliberal, da ideologia do Vale do Silício e suas disputas de 
sentido. São as facetas discursivas e produtivas da arquitetura que rege o capitalismo em seu estágio atual: os sentidos sobre o que dizer e como fazer para ser alguém de sucesso, com fórmulas convocatórias que prescrevem não somente modos de dizer, mas modos de ser e produzir. Essas prescrições nem sempre se efetivam nas materialidades do trabalho, o que faz com que haja lutas e disputas pelos sentidos dessas prescrições a partir de suas ressignificações no mundo do trabalho. Mas o circuito do trabalho - enquanto cadeia produtiva de valor - é desenhado para ser a cristalização da gramática do capital.

\section{LUTAS POR CIRCULAÇÃO}

Se a comunicação é lugar de disputas, envolvendo circulação de sentidos e circulação do capital, é preciso entrever as lutas por circulação. Que modos outros há de fazer circular a vida em sociedade para além do realismo capitalista? Como modificar chaves de sentido em um domínio quase completo da racionalidade neoliberal (BROWN, 2016; DARDOT; LAVAL, 2016)? Longe de ser um ponto pacífico na circulação do capital, a comunicação pode ser um palco para circulação das lutas, que de acordo com Dyer-Witheford (2016), é marcada por tentativas

\footnotetext{
da cibernética de se reapropriar dos manifestantes, grevistas e ativistas e vários tipos ao longo do mundo, ainda não foi capaz de compilar uma força organizada capaz de mudar o equilíbrio das forças de classes, fornece algumas dicas para uma resistência proletária com muitas frentes, e está em uma tarefa que a pesquisa em comunicação precisa se aprofundar.
}

A circulação das lutas no âmbito da circulação comunicacional do capital envolve ainda as tentativas da circulação do comum (DE PEUTER; DYER-WITHEFORD, 2010) de brechas ou fissuras no modo de produção capitalista, enquanto circuitos de acumulação e resistência. Como diz Harvey (2018, p. 56), "as lutas políticas e sociais contra o poder do capital na totalidade da circulação do capital assumem diferentes formas e exigem diferentes tipos de aliança estratégica para ter sucesso". Lutas em torno da circulação do capital que podem trazer tanto constrangimentos quanto brechas para ações em busca de outros mundos. Desta forma, as lutas que se dão na circulação do capital envolvem não só as disputas internas, mas modos de fazer circular o comum.

Os processos comunicacionais, nesse sentido, não são apenas articuladores dos modos de ser e aparecer do capital. A circulação das lutas no âmbito da circulação comunicacional do capital envolve brechas ou fissuras no modo de produção capitalista, enquanto circuitos de acumulação e resistência. Lutas em torno da circulação do capital que podem trazer tanto constrangimentos quanto brechas para ações em busca de outras circulações de sentidos.

O primeiro passo para compreensão da circulação do comum é não idealizar o comum nessa relação com o modo de produção capitalista. Não é um mundo à parte, mas algo que envolve as condições concretas e materiais dos sujeitos sociais, com suas tensões e contradições. É preciso pensar em mediações possíveis, sem, contudo, naturalizar o "realismo capitalista" (FISHER, 2011). O comum deve ser algo que permita entrever além do capitalismo, "não o surgimento de uma ideia comunista eterna, mas o surgimento de uma forma nova de contestar o capitalismo, ou mesmo de considerar sua superação" (DARDOT; LAVAL, 2017, p. 17). 
A circulação do comum só se efetiva em meio à circulação das lutas, enquanto algo, ao mesmo tempo, político, cultural, linguístico e econômico - articulados com a comunicação. Propomos uma noção que vá além da ideia de recursos compartilhados que geram formas de cooperações sociais e aquém de uma ideia vinculativa originária aos seres humanos. Uma visada de médio alcance que permita, justamente, relacionar circulação do capital e circulação do comum em suas perspectivas comunicacionais. Reinserir o comum nos processos produtivos e comunicacionais, considerando a "co-atividade" como obrigação política (DARDOT; LAVAL, 2017).

Uma visão dialética do comum permite considerá-lo em suas contradições. O circuito do comum, no ambiente macrossocial contemporâneo, nunca estará totalmente apartado da circulação do capital. São escapes, frestas e brechas. Possibilidades, fissuras e tentativas. As lutas no âmbito da circulação do capital, para Harvey (2018, p. 56), tanto podem "constrange[r] quanto facilita[r] certas formas de pensamento e ação". É uma dialética entre expressão e exploração envolvendo a circulação do capital e circulação do comum. O reconhecimento dessas tensões é crucial para disputar sentidos e fazer circulá-los em relação ao comum.

Uma dessas possibilidades é considerar o comum como uma forma de "utopia real", nos termos de Wright (2010), reconhecendo as limitações em relação às possibilidades de transcender o capitalismo, mas com senso de possibilidade real de mudança social. Para ele, é preciso pensar perspectivas plausíveis de alternativas radicais rumo a uma mudança social que seja emancipatória. Observar e atuar em possibilidades de utopias reais rumo à circulação do comum é procurar circular outros sentidos além da racionalidade neoliberal e seus modos de ser e aparecer. Entrar nas disputas.

No contexto de capitalismo de plataforma, pensar a circulação do comum pode contemplar projetos reformistas como o cooperativismo de plataforma (SCHOLZ, 2017; GROHMANN, 2018), desde que seja uma brecha para ir além e compreender as cooperativas como projeto prefigurativo e radical (FENTON, 2016; SANDOVAL, 2019). Há também possibilidades de imaginar expropriação das plataformas digitais pelos trabalhadores (CANT, 2019) e reapropriação das tecnologias das plataformas digitais para fins socialistas (PHILLIPS; ROSWORSKI, 2019). Esses processos ainda estão em construção, mas apresentam possibilidades prefigurativas de outros mundos possíveis, não como algo que permaneça no micro-rizomático, mas que se espraie como sementes para outras formas de ser e estar no mundo.

\section{CONSIDERAÇÕES FINAIS}

Propusemos, neste artigo, discutir o papel da comunicação na circulação do capital, componente central para compreender o processo de plataformização, entendida como a crescente dependência dessas infraestruturas digitais para as mais diversas atividades, dentre as quais a comunicação e o trabalho. Para isso, é central compreender as plataformas como meios e tecnologias de produção, comunicação e circulação.

Essa aceleração nos circuitos do capital é parte central do seu modo de sobrevivência. Isso se acentua em um contexto de pandemia, em que o capital busca acelerar ainda mais processos que estavam em andamento, como trabalho remoto, educação à distância e vigilância digital. É a partir do combo meio de produção-meio de comunicação, sustentado pelos proprietários dos conglomerados das 
plataformas, que podem ocorrer lives e reuniões on-line, com a ainda maior intensificação das atividades de trabalho, para que não reste tempo morto.

A comunicação se efetiva na circulação do capital como modo de organização que tem facetas materiais e discursivas, enquanto linguagem e trabalho em circulação. Ela materializa e naturaliza os modos de viver e ser no capitalismo por meio de uma racionalidade neoliberal empreendedora que parece inescapável. Junta-se a ela que é a partir da comunicação que a financeirização assenta suas bases no rentismo incorporado às plataformas digitais. $O$ fato de a maioria as empresas entre as top 20 serem da área de tecnologia, conforme mostra Sadowski (2020), evidencia que o modelo de comunicação-produção se espraia por todas as áreas, inclusive saúde e petróleo.

Sem a comunicação não há dataficação ou intensa circulação de dados nos processos de produção, circulação e consumo. Não há valor em dados soltos, mas, justamente, em sua organização. E é a comunicação que organiza os dados para serem lidos a partir do combo racionalidade neoliberal-financeirização. Os mecanismos de extração-extrativismo de dados pelas plataformas digitais, como expropriação de recursos de forma generalizada e produtiva em relação aos modos de vida das periferias globais (ABÍLIO, 2020) são o resultado da centralidade da comunicação na circulação do capital.

Porém, isso não significa que os sentidos em circulação não estejam em disputa por tentativas, brechas e alternativas em relação a outros mundos possíveis. Pois considerar a comunicação como um fazer organizativo significa que ela também abre brechas para a circulação dos trabalhadores (ENGLERT; WOODCOCK; CANT, 2020). O que destacamos aqui é o que está por trás de nossas investidas empíricas atuais sobre trabalho digital. Isso aparece tanto quando estamos dedicados a compreender condições de trabalho nas plataformas digitais quanto nos envolvemos na análise de movimentações como as lutas por organização coletiva de trabalhadores, movimentos de autogestão, cooperativismo e regulação do trabalho. Todos são movimentos recheados de possibilidades, limites e contradições.

O envolvimento dos pesquisadores com o papel da comunicação na circulação do capital e dos trabalhadores não significa somente uma análise de seus múltiplos sentidos, mas um repensar em perspectiva radical a teoria e a pesquisa em comunicação em busca de formas de atuação na realidade material e concreta, em conformidade com o que Englert, Woodcock e Cant afirmam em relação ao operaísmo digital. Esta é a base epistemológica para que a "periculosidade social da ciência" (VIEIRA PINTO, 1979) aflore em formas de pesquisa ação, intervenção e participante.

Artigo recebido em 02/02/2020 e aprovado em 14/04/2020.

\section{REFERÊNCIAS}

ABÍLIO, Ludmila Costhek. Plataformas digitais e uberização: a globalização de um Sul administrado? Contracampo. V. 39, n. 1, 2020.

ANTUNES, Ricardo. O Privilégio da Servidão. São Paulo: Boitempo, 2018.

BEER, David. Metric Power. London: Palgrave, 2016.

BERARDI, Franco. The Uprising: on poetry and finance. Cambridge: MIT Press, 2012. 
BOLAÑO, César; VIEIRA, Eloy. Economia política da internet e os sites de redes sociais. Eptic. V. 16, n. 2, 2014.

BOURDIEU, Pierre. A Distinção. Porto Alegre: Zouk, 2007.

BREITER, Andreas.; HEPP, Andreas. The Complexity of Datafication: putting digital traces in context. In: HEPP, A.; BREITER, A.; HASEBRINK, U. (org.). Communicative Figurations. London: Palgrave, 2018. p. 387-405.

BROWN, Wendy. El Pueblo Sin Atributos. Barcelona: Malpaso, 2016.

CANT, Callum. Riding for Deliveroo. London: Polity, 2019.

CASAQUI, Vander. A Inspiração como Forma Comunicacional do Capitalismo Cool. Anais do Intercom. São Paulo/SP: ECA-USP, 2016.

COULDRY, Nick. Media: why it matters. London: Polity, 2019.

; MEJIAS, Ulises. The Costs of Connection. Palo Alto: Stanford, 2019.

DANTAS, Marcos. Mais valia 2.0: produção e apropriação de valor nas redes do capital. Eptic. V. 16, n. 2, 2014.

DARDOT, Pierre; LAVAL, Christian. A Nova Razão do Mundo. São Paulo: Boitempo, 2016.

. Comum. São Paulo: Boitempo, 2017.

DEAN, Jodi. Communicative Capitalism: circulation and the foreclosure of politics. In: BOLER, Megan (org.). Digital Media and Democracy. London: MIT Press, 2008, p. 101122.

DE PEUTER, Greig; DYER-WITHEFORD, Nick. Commons and Cooperatives. Affinities. V. 4, N. 1, 2010, p. 30-56.

DYER-WITHEFORD, Nick. Cyber-Proletariat. London: Pluto Press, 2016.

2019. ; KJOSEN, Atle; STEINHOFF, James. Inhuman Power. London: Pluto Press,

ENGLERT, Sai; WOODCOCK, Jamie; CANT, Callum. Operaísmo digital: tecnologia, plataformas e circulação das lutas dos trabalhadores. Fronteiras - Estudos Midiáticos. V. 22, n. 1, 2020.

FENTON, Natalie. Digital, Political, Radical. London: Polity, 2016.

FIGARO, Roseli. Comunicação e trabalho: implicações teórico-metodológicos. Galáxia. V. 39, 2018.

FISHER, Mark. Capitalist Realism. Winchester: Zero Books, 2011.

FUCHS, Christian; SANDOVAL, Marisol. Digital workers of the world unite! A framework to critically theorising and analysing digital labour. TripleC. V. 22, n. 2, 2014.

GOUX, Jean-Joseph. Économie et symbolique. Paris: Éditions du Seuil, 1973.

GRAHAM, Mark (org.). Digital Economies at Global Margins. Massachussets: MIT Press, 2019.

GROHMANN, Rafael. Cooperativismo de plataforma e suas contradições: análise de iniciativas da área de comunicação no Platform.Coop. Liinc em Revista. V. 14, n. 1, 2018. 
- Plataformização do trabalho: entre dataficação, financeirização e racionalidade neoliberal. Revista EPTIC. V. 22, n. 1, 2020.

n. 1, 2020.

; QIU, Jack. Contextualizando o trabalho em plataformas. Contracampo. V. 39,

HARVEY, David. A Loucura da Razão Econômica. São Paulo: Boitempo, 2018.

HUWS, Ursula. Labor in the Contemporary Capitalism. London: Palgrave, 2019.

ILLOUZ, Eva. O Amor nos Tempos do Capitalismo. Rio de Janeiro: Zahar, 2011.

LUKÁCS, Gyorgy. Para uma Ontologia do Ser Social I. São Paulo: Boitempo: 2012.

MARAZZI, Christian. Capital and Affects. Los Angeles: Semiotext(e), 2011.

MARX, Karl. Grundrisse. São Paulo: Boitempo, 2011.

. O Capital: Livro I. São Paulo: Boitempo, 2013.

. O Capital: Livro II. São Paulo: Boitempo, 2014.

. O Capital: crítica da economia política - Livro III. São Paulo: Boitempo, 2017.

MOROZOV, Evgeny; BRIA, Francesa. A Cidade Inteligente. São Paulo: UBU, 2019.

MURDOCK, Graham. Media Materialties: for a moral economy of machines. Journal of Communication. V. 68, n. 2, 2018.

NOUROUDINE, Abdallah. A linguagem: dispositivo revelador da complexidade do trabalho. In: SOUZA E SILVA, Maria Cecília; FAITA, Daniel (org.). Linguagem e Trabalho. São Paulo: Cortez, 2002.

PHILLIPS, Leigh; ROZWORSKI, Michal. The People's Republic of Walmart. London: Verso, 2019.

ROSSI-LANDI, Ferruccio. A Linguagem como Trabalho e como Mercado. São Paulo: Difel, 1985

QIU, Jack; GREGG, Melisa; CRAWFORD, Kate. Circuits of Labour: a labour theory of the iPhone era. TripleC. V. 12, N. 2, 2014.

SADOWSKI, Jathan. When data is capital: datafication, accumulation and extraction. Big Data \& Society. 2019.

. The Internet of landlords: digital platforms and new mechanisms of rentier capitalism. Antipode. 2020.

SANDOVAL, Marisol. Entrepreneurial Activism? Platform Cooperativism Between Subversion and Co-optation. Critical Sociology. 2019.

SCHOLZ, Trebor. Cooperativismo de Plataforma. São Paulo: Rosa Luxemburgo, 2017.

SCHRADIE, Jen. Ideologia do Vale do Silício e Desigualdades de Classe. Parágrafo. V. 5, 2017.

SOHN-RETHEL, Alfred. Intelectual and Manual Labor: a critique of epistemology. New Jersey: Humanities Press, 2017.

SRNICEK, Nick. Platform Capitalism. London: Polity, 2017.

VAN DIJCK, José; POELL, Thomas; DE WAAL, Martijn. The Platform Society. New York: Oxford, 2018.

VIEIRA PINTO, Álvaro. Ciência e Existência: problemas filosóficos da pesquisa científica. Rio de Janeiro: Paz e Terra, 1979. 
VIEIRA PINTO, Álvaro. O Conceito de Tecnologia - vol. I. Rio de Janeiro: Contraponto, 2005.

WAJCMAN, Judy. Pressed for Time. Chicago: University of Chicago Press, 2015. . How Silicon Valley Sets Time. New Media \& Society. V. 21, n. 6, 2019.

WILLIAMS, Raymond. Cultura e Materialismo. São Paulo: Unesp, 2011.

WOODCOCK, Jamie. Marx at the Arcade. Chicago: Haymarket Books, 2019. ; GRAHAM, Mark. Gig Economy: a critical introduction. London: Polity, 2019.

WRIGHT, Erik Olin. Envisioning Real Utopias. New York: Penso, 2010.

ZUBOFF, Shoshana. The Age of Surveillance Capitalism. London: Profile Books, 2019. 